\title{
Смаковская Н.И.
}

Нижегородский государственный технический университет им. Р.Е. Алексеева

\section{ДИАГНОСТИКА КОММУНИКАТИВНО-ДЕЯТЕЛЬНОСТНОГО КОМПОНЕНТА ПСИХОЛОГИЧЕСКОЙ КУЛЬТУРЫ ПРЕПОДАВАТЕЛЯ ТЕХНИЧЕСКОГО ВУЗА}

Аннотация. В статье обсуждается вопрос изменения требований к содержанию психологической культуры как основы совершенствования профессионализма преподавателя технического вуза. Автор сосредотачивается на изучении профессиональных коммуникативных действий в структуре психологической культуры преподавателя вуза, представляет характеристику коммуникативно-аналитических, диагностических и проективных действий в структуре изучаемого феномена: разработана и апробирована методика оценки; представлены результаты диагностики среднеуровневого показателя проявления коммуникативно-деятельностного компонента и их интерпретация.

Ключевые слова: психологическая культура преподавателя, структура коммуникативнодеятельностного компонента психологической культуры, коммуникативно-аналитические действия (КАД), коммуникативно-диагностических действия (КДД), коммуникативнопроективные действия (КПД).

\author{
N. Smakovskaya \\ Nizhny Novgorod State Technical University n.a. R.E. Alekseev
}

\section{DIAGNOSTICS OF COMMUNICATIVE AND ACTIVITY COMPONENT OF UNIVERSITY TEACHERS' PSYCHOLOGICAL CULTURE}

Abstract. The article discusses the issue of changing the requirements to the conceptual parameters of the psychological culture of a technical university teacher. The author focuses on the study of professional communicative activities in the structure of a university teacher's psychological culture. The communicative and analytical actions, as well as the diagnostic and projective ones are characterized in the structure of the studied phenomenon. The methodology of assessing the diagnostic results of the communicative-activity components index and its interpretation is developed and approved.

Key words: university teacher's psychological culture, the structure of communicative-activity component of psychological culture, communicative and analytical activities (CAA), communicative and diagnostic activities (CDA), communicative and projective activities (CPA).

Проблемы преобразования современной высшей школы, повышения эффективности профессиональной деятельности преподавателя вуза создают предпосылки для разработки новых научных подходов к исследованию его труда. Особое внимание психологической науки заслуживает изучение психологической культуры современного преподавателя высшей школы как личностной

(с) Смаковская Н.И., 2015. 
детерминанты развития его профессионализма.

Во многих исследованиях отмечается, что внутренняя гармонизация и соразмерность всех структур личности педагога достигается, прежде всего, в результате максимального развития качеств, определяющих доминирующую направленность его личности, придающую смысл его профессиональной деятельности [6]. Учеными подчеркивается, что именно педагогическая направленность личности способна обеспечить такую органичную соразмерность и пропорциональность, которая характеризуется ориентированностью преподавателя в педагогическом взаимодействии на развитие индивидуальных личностных и профессиональных качеств и способностей как студента, так и своих в интересах студента.

Отметим актуальность обращение к данной проблематике в современной социоэкономической и культурной ситуации. Агрессивное влияние социальной среды, деструктивных процессов, происходящих в ней, разрушительно воздействует, прежде всего, на личность молодого человека. Учеными подчеркивается, что в минимизации негативных социальных последствий и их преодолении ключевая роль принадлежит педагогу, в том числе преподавателю высшей школы. Он, по мысли Л.М. Митиной [3], «может и должен способствовать активному распространению положительного нравственного опыта», создавать необходимые условия для поиска молодым человеком путей собственного личностного и профессионального самоопределения.

Психолого-педагогические исследования доказывают очевидную истину о том, что интерес к предмету зачастую определяется неуловимыми взаимосвязями, которые устанавливаются между субъектами образовательного пространства [2]. Исследователи отмечают, что эффективное профессиональное педагогическое общение, обеспечивающее оптимальное развитие образовательного процесса, обладает рядом уникальных особенностей: яркой палитрой коммуникативных задач, открытой позицией субъектов образовательной ситуации, преобладание организующего воздействия преподавателя над дисциплинирующим.

Авторами на основе анализа и систематизации ситуаций затрудненного общения (решение профессиональных задач проблемного типа) обозначена необходимость разработки «праксиологического конструкта» [5, с. 296], благодаря которому можно будет максимально точно и оперативно решать поставленные коммуникативные задачи, которые отличаются необходимостью проникновения в механизм возникновения проблемы, установления причинно-следственного соответствия, нахождения дополнительной информации и принятия решения в ситуации выбора из нескольких альтернатив, ограниченности времени и неопределенных условий. Обращение автора к проблеме изучения коммуникативного аспекта психологической культуры преподавателя технического вуза определяется во многом переосмыслением личностной и профессиональной позиции преподавателя высшей профессиональной школы в условиях личностного и профессионального взаимодействия в контексте педагогической психологии [4]. В определении психологической культуры 
преподавателя высшей технической школы мы исходим из осознания данного феномена как сложной и многомерной реальности, характеризующей преподавателя как профессионала и личность, интегрирующую психологические знания в ракурсе преподавания своего предмета, осуществляя продуктивное профессионально-личностное общение со студентами, осознавая потребность в совершенствовании своего профессионализма. Структуру коммуникативно-деятельностного компонента психологической культуры преподавателя вуза мы представляем как систему профессиональных коммуникативно-аналитических, коммуникативно-диагностических и проективных действий [6], содержательные характеристики которых определены следующим образом:

- коммуникативно-аналитические действия (КАД) рассматриваются как сложная аналитико-синтетическая процедура восприятия и осознания существенных признаков ситуации и установление в ней тех отношений и свойств, распознание которых необходимо для решения педагогической задачи в данной коммуникативной обстановке;

- коммуникативно-диагностические действия (КДД) позволяют преподавателю соотносить существующую коммуникативную ситуацию, ее социально-психологическое наполнение с развивающим личностным и профессиональным потенциалом предметного содержания дисциплины;

- коммуникативно-проективные действия (КПД) предполагают создание (воссоздание) коммуникативных образцов в условиях, адекватным динамике развития коммуникативной ситуации, а также моделирование программы совершенствования преподавателем как собственной психологической культуры, так и психологической культуры студентов.

С целью изучение актуального уровня коммуникативных действий в структуре психологической культуры преподавателя технического вуза мы разработали и апробировали методику «Оценка коммуникативно-деятельностного компонента психологической культуры преподавателя технического вуза» (методика основана на решении практических заданий).

Преподавателям различных кафедр технического университета, участвовавшим в диагностике $(\mathrm{n}=120)$, было предложено выполнить серию последовательно предъявляемых заданий, каждое из которых являлось логичным продолжением предыдущего. За выполненные задания возможно было получить от ноля до трех баллов, руководствуясь представленными далее содержательными характеристиками.

Так, результат решения практического задания, оцененный «0 баллов» соответствовал критическому уровню развития коммуникативнодеятелностного компонента психологической культуры преподавателя вуза. Это проявилось, прежде всего, в отсутствии осознания взаимосвязей аналитических, диагностических и проективных действий как значимых в психологической культуре преподавателя технического вуза. Профессиональные коммуникативные действия не были включены в систему личностного и профессионального целеполагания, поэтому профессионально-педагогическая деятельность осуществляется исходя из решений 
собственных краткосрочных задач, не связанных с личностным и профессиональным совершенствованием студентов. В ответах преподавателей отсутствовали адекватные модели педагогического взаимодействия, отмечено исключительное доминирование субъект-объектных коммуникаций.

Один балл получили ответы преподавателей, соответствующие низкому уровню развития коммуникативно-деятельностного компонента. Это проявлялось в том, что в процессе решения задачи преподаватели не смогли реализовать весь комплекс интеллектуальных и практических коммуникативных действий (обозначение характерных признаков той или иной коммуникативной модели, выявление возможности ее реализации в данной педагогической ситуации). Выбор коммуникативных действий преподавателем не был аргументирован заданными коммуникативными параметрами.

Оценка «2 балла» (средний уровень) соответствовала результату, в котором присутствовали такие содержательные характеристики развития коммуникат ивно-деятельностного компонента психологической культуры, как наличие цели и результатов своих коммуникативных действий, прогнозирование действий студентов, управление ситуацией, в целом направленное на нейтрализацию ситуации затрудненного общения. Однако преподаватель не всегда исходит из актуального уровня развития психических особенностей студентов данного возраста, затрудняясь в соотнесении диагностических признаков коммуникативной ситуации с предметным содержанием занятия; не всегда обосновывает данный выбор определенной коммуникативной моделью; не рассматривает данную коммуникативную ситуацию в качестве стимулирующей.

Ответы преподавателей, соответствующие максимальному уровню развития коммуникативно-деятельностного компонента, были оценены в «3 балла». Данные результаты свидетельствовали о глубоком понимании и оптимальной реализации преподавателем системы профессионально важных коммуникативно-аналитических, коммуникативно-диагностических и коммуникативно-проективных профессиональных действий. Это предполагало эффективное управление коммуникативной ситуацией (определение причин ее возникновения, постановка педагогических целей и задач; учет особенностей обучающихся; описание возможных ответных реакций студентов, предвидение результатов воздействия). Преподаватель соотносил диагностические признаки ситуацию с предметным содержанием занятия для эффективного личностного и профессионального развития студентов; обосновывал данный выбор определенной коммуникативной моделью; рассматривал данную коммуникативную ситуацию в качестве стимулирующей.

Представим в целом серию диагностических заданий. Первое задание заключалось в анализе коммуникативной ситуации по предложенному алгоритму: определить педагогическую проблему, выявить ее значимые показатели, специфику педагогической ситуации, ее существенные признаки, определить свои действия по достижению личностного развивающего эффекта.

Во втором задании преподавателям было предложено соотнести содер- 
жательные специфические признаки коммуникативной ситуации с психологическими особенностями развития студентов и студенческой группы.

Третье задание предполагало выявление возможностей преподавателей по определению диагностических признаков педагогической ситуации и разработке сценария корректирующего коммуникативного воздействия.

Четвертое и пятое задание были направлены на диагностику, прежде всего, коммуникативно-проективных действий. Так, преподавателям было предложено построить развернутый и детализированный план беседы со студентом, сопоставив этап беседы, содержание коммуникативных действий и вербальные/невербальные иллюстрирующие примеры.

В завершающем задании преподаватели разрабатывали программу личностного и профессионального развития для студента. Преподавателям предлагалось обозначить психологическую проблему, определить цель возможных личностных и профессиональных изменений, охарактеризовать исходное состояния субъекта, выявить основные признаки инновационной среды, обозначить ожидаемые личностные и профессиональные изменения.

Анализ содержания выполненных преподавателями заданий позволил нам обозначить проблему: наиболее сложной для большинства преподавателей оказалась та часть предложенных заданий, в которой надо было продемонстрировать не эмоциональную оценку ситуации и общие рассуждения, а представить анализ коммуникативной ситуации в соотнесении с предметным содержанием дисциплины, ее дифференцированную характеристику и коммуникативный диагностический потенциал.

При решении первого задания (среднеуровневый показатель проявления коммуникативно-деятельностного компонента (СУП) = 1,5 ), предполагающего глубокий и всесторонний анализ педагогической ситуации, включающий определение проблемы и объективных/субъективных условий ее возникновения, осознание специфики педагогической ситуации и реализацию содержательных коммуникативных действий, соответствующих особенностям развития студентов в заданных коммуникативных условиях, полностью справились с заданием 10,2 \% преподавателей. Наибольшее число преподавателей справилось с заданием частично, причем у 42,1 \% в ответах доминировал оценочный тип высказываний на общем эмоциональном фоне. Преподаватели затруднились и в определении признаков специфической коммуникативной ситуации и не ответили на вопрос о необходимых действиях по достижению требуемого развивающего эффекта. Эти же вопросы вызвали затруднения у 39,2 \% преподавателей, однако в их ответах преобладал анализ и осознание возможности изменений с качественным их обоснованием. 8,5 \% преподавателей не смогли полностью справиться с заданием, в ответах у них присутствовала лишь острая негативная эмоциональная реакция, которая свидетельствовала о нежелании «работать, входить» в данную ситуацию.

Примерно такие же результаты $($ СУП=1,49) были получены при выполнении задания на сопоставление содержательной характеристики выяв- 
ленной коммуникативной проблемы и ее специфических признаков с психологическими особенностями студентов и социально-психологическими показателями развития студенческой группы. Чуть более 10 \% преподавателей справились с заданием; 8,7 \% преподавателей отказались от выполнения данного задания или не справились с ним. В ответах 42,5 \% преподавателей преобладали эмоционально-оценочные действия, что не позволило им ориентироваться в ситуации, вычленять и обобщать ее диагностические признаки. 38,7 \% преподавателей, участвовавших в диагностике, в решении задания проявили коммуникативные действия по соотнесению характерных признаков коммуникативной ситуации с психологическими особенностями ее субъектов лишь частично.

Достаточно сложным $($ СУП $=1,46)$ оказалось задание по разработке приемов коммуникативного воздействия с целью коррекции педагогической ситуации в соответствии с ее коммуникативными диагностическими признаками. В полном объеме с ним справилось 9,7 \% преподавателей: ими были представлены варианты вербальных и невербальных модулей с их обоснованием в соответствии с коммуникативно-диагностическими признаками ситуации. 10,5 \% преподавателей не включились в выполнение задания, или задание вызвало у них резко негативную реакцию. 42,4 \% преподавателей описывали коммуникативные коррекционные средства, ориентируясь, прежде всего, на авторитарную субъект-объектную модель педагогического взаимодействия; признаки субъектсубъектной модели педагогического взаимодействия с учетом личностной и профессиональной коррекции педагогической ситуации были выявлены в ответах 37,4 \% преподавателей, принимавших участие в исследовании.

Еще более затруднительным (СУП = $1,39)$ стало выполнение задания по разработке структурированного и детализированного плана беседы со студентом. В данном задании предполагалось соотнесение определенного ее этапа с содержанием коммуникативных действий и вербальными/невербальными иллюстрирующими примерами. $\mathrm{He}$ справилось с заданием 12,3 \% преподавателей. 44 \% преподавателей продемонстрировали коммуникативные аналитические, диагностические и проективные действия по изменению мотивационно-ценностного компонента психологической культуры студенты весьма скудно. Частичная представленность всего комплекса действий коммуникативно-деятельностного компонента выявлена у 35,2 \% преподавателей. В полном объеме данное задание выполнило 8,5 \% преподавателей, предложив аргументированные варианты ответов в соответствии с личностным и профессиональным уровнем развития студента, реализуя обучающий потенциал коммуникативных условий педагогической ситуации.

Наиболее сложным (СУП = 1,37) для преподавателей, участвовавших в диагностике, оказалось задание, в котором предлагалось представить программу совершенствования психологической культуры для студента. Подавляющая часть преподавателей (более 70 \%) смогла предложить лишь частичные ответы на некоторые вопросы задания: наибольшие затруднения вызвали такие параметры, как определение цели предполагаемых личност- 
ных и профессиональных изменений у студента, признаков инновационной среды и ожидаемые личностные и профессиональные изменения.

Таким образом, полученные результаты позволили нам сделать ряд выводов. Наиболее сложными оказались задания, направленные на диагностику всего комплекса профессиональных коммуникативных действий, что подразумевает, прежде всего, демонстра- цию детальный и аргументированный анализ коммуникативной ситуации, определение характерных коммуникативных диагностических признаков. Большинство преподавателей, принимавших участие в диагностике, продемонстрировали минимальный и средний уровни развития коммуникативно-деятельностного компонента психологической культуры (рис. 1).

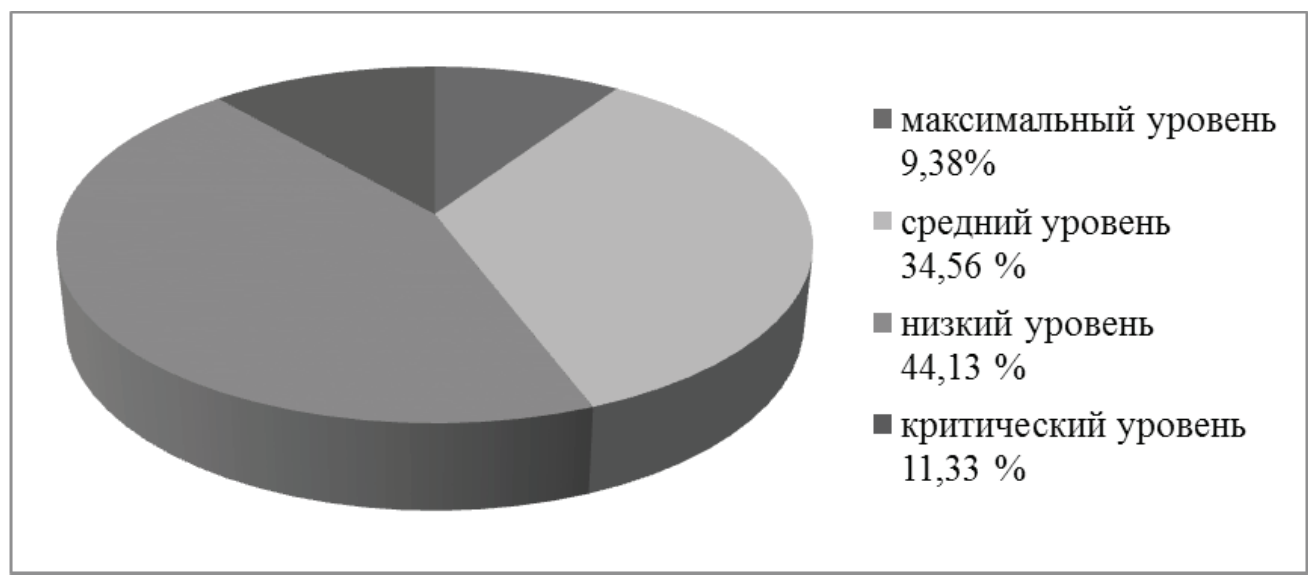

Puc. 1. Результаты диагностики актуального уровня развития коммуникативных действий в структуре психологической культуры преподавателя вуза

При этом многими преподавателями осознавалась необходимость «преобразования природных возможностей и образования новых способностей» $[1$, с. 141] в своей психологической культуре, ее постоянное творческое самосовершенствование, поскольку психологические механизмы развития (как качественного преобразования) принципиально отличаются от механизмов формальной передачи знаний, умений и навыков.

\section{ЛИТЕРАТУРА:}

1. Зинченко В.П. Психологическая педагогика. Самара, 1998. 216 с.
2. Леонтьев Д.А., Ханина И.Б. К проблеме общения в работах А.А. Леонтьева // Культурно-историческая психология. 2011. № 1. С. 20-27.

3. Митина Л.М. Смысл жизни как рефлексивный ресурс личностно-профессионального развития педагога // Вестник Московского государственного областного университета. Серия: Психологические науки. 2014. № 3. С. 81-89.

4. Смаковская Н.И. Изучение психологической культуры преподавателя технического вуза на основе анализа аудиторного занятия // Научные ведомости Белгородского государственного университета. Серия «Гуманитарные науки». 2014. Вып. 23. № 20 (191). С. 87-90. 
5. Современные образовательные технологии : учеб. пособие / коллектив авторов; под ред. Н.В. Бордовской. 3-е изд., стер. М., 2013. 432 с.
6. Сорокина Т.М. Развитие профессиональной компетенции будущих учителей начальной школы. Н. Новгород, 2002. 169 c. 